\title{
Perception of and anxiety about COVID-19 infection and risk behaviors for spreading infection: an international comparison
}

\author{
Akihiro Shiina ${ }^{1 *} \mathbb{D}$, Tomihisa Niitsu², Osamu Kobori ${ }^{3}$, Keita Idemoto ${ }^{2}$, Tasuku Hashimoto ${ }^{4}$, Tsuyoshi Sasaki $^{2}$, \\ Yoshito Igarashi ${ }^{1}$, Eiji Shimizu ${ }^{5}$, Michiko Nakazato ${ }^{4}$, Kenji Hashimoto ${ }^{1}$ and Masaomi lyo ${ }^{1,2}$
}

\begin{abstract}
Background: To control the spread of the new SARS-CoV-2 infection's disease (COVID-19), appropriate precautionary behaviors by the public should be promoted. There are international differences in public cognitive and behavioral pattern, attitudes toward information sources, and anxiety about COVID-19. Information about these differences could increase understanding of the patterns of epidemic-related anxiety and behavior, and would help optimize future policies for preventing the next wave of the epidemic.

Methods: To examine between-country differences in perception, attitude, and precautionary behaviors toward COVID-19, we conducted a cross-sectional study using an online questionnaire survey. Participants were adults who had been registered in Cross Marketing Group Inc. and living in the UK, Spain, or Japan. A total of 8,000 people stratified by age were recruited on a first-come, first-serve basis. Knowledge of and anxiety about COVID-19, the frequency of access and perceived credibility of several information sources, and the frequency of each precautionary behavior were examined on March 27-28, 2020, in Japan and April 17-21, 2020, in the UK and Spain.

Results: Knowledge, anxiety, and the frequency of precautionary behaviors were higher in the UK and Spain than in Japan. Participants with infected acquaintances were more concerned about COVID-19. However, participants in the UK rarely wore a medical mask. Participants in the UK and Spain were more eager to obtain information about COVID-19 than those in Japan. Participants in Spain tended not to trust official information and to believe specialists' comments instead.
\end{abstract}

Conclusion: The rapidity of the spread of COVID-19, cultural background, and recent political situations seemed to contribute to the international differences here.

Keywords: COVID-19, Anxiety, Precautionary behaviors, International comparison, Questionnaire survey

\section{Background}

In December 2019, a novel species of coronavirus that causes very specific and critical pneumonia was identified: SARS-CoV-2. The virus spread worldwide within several months, leading to millions of infections, and the

\footnotetext{
*Correspondence: shiina-akihiro@faculty.chiba-u.jp

${ }^{1}$ Center for Forensic Mental Health, Chiba University, 260-8670 Inohana

1-8-1, Chuo-ku, Chiba, Japan

Full list of author information is available at the end of the article
}

World Health Organization (WHO) declared a pandemic state on March 11, 2020. Citizens in many countries now face the risk of serious disease caused by SARS-CoV-2, i.e., COVID-19. Precautionary behaviors are important in reducing the risk of COVID-19 transmission. However, there are differences between countries in public attitudes, behaviors, and anxiety toward COVID-19.

Facing uncertain situations can increase anxiety levels, especially if there is potential mortality risk. Anxiety may lead both healthy and vulnerable individuals to engage

c) The Author(s) 2021. This article is licensed under a Creative Commons Attribution 4.0 International License, which permits use, sharing, adaptation, distribution and reproduction in any medium or format, as long as you give appropriate credit to the original author(s) and the source, provide a link to the Creative Commons licence, and indicate if changes were made. The images or other third party material in this article are included in the article's Creative Commons licence, unless indicated otherwise in a credit line to the material. If material is not included in the article's Creative Commons licence and your intended use is not permitted by statutory regulation or exceeds the permitted use, you will need to obtain permission directly from the copyright holder. To view a copy of this licence, visit http://creativeco mmons.org/licenses/by/4.0/. The Creative Commons Public Domain Dedication waiver (http://creativecommons.org/publicdomain/ zero/1.0/) applies to the data made available in this article, unless otherwise stated in a credit line to the data. 
in behaviors to protect themselves from contracting the virus [1]. Jones and Salathé reported that engagement in protective behaviors shows individual variation and may be affected by several factors [2]. A community-based survey by Harper et al. indicated that fear of COVID-19 was the only predictor of positive behavior changes [3].

Recent studies suggest that some super-spreaders unintentionally transmit the virus because of their hyperactivity $[4,5]$. These individuals are unlikely to be anxious about infection and tend not to listen to or trust official government information [6].

According to the WHO, SARS-CoV-2 is transmitted during close contact via respiratory droplets (e.g., during coughing) and by fomites [7]. To prevent the transmission of SARS-CoV-2, the WHO recommends frequent hand hygiene, use of respiratory protection, regular cleaning and disinfection of surfaces, maintenance of physical distances, and avoidance of people with fever or respiratory symptoms [2]. Based on these recommendations, most countries have addressed the outbreak according to local circumstances and have attempted to manage the accompanying economic downturn. However, the development of further strategies for greater control of the pandemic is required.

Appropriate provision of accurate information is essential if governments are to encourage citizens to follow appropriate behaviors to prevent the spread of COVID19. However, there are regional differences in public responses to the pandemic [8]. There are also international differences in public cognitive and behavioral patterns, attitudes toward information sources, and anxiety about the COVID-19 pandemic. Information about these differences could contribute to our understanding of patterns of epidemic/pandemic-related anxiety and behavior, and would help optimize future policies for preventing the next wave of the epidemic.

\section{Materials and methods}

We conducted a series of web-based cross-sectional surveys to determine international differences in the perceptions and behaviors of the population in the current COVID-19 risk situation. We asked a market research company, Cross Marketing Group Inc., to recruit a total of 8,000 individuals for this series of surveys, which were conducted in two stages. Participants had to be over 20 years old. As the study aim was to examine individuals' perception and anxiety regarding COVID-19, we excluded people who had experience of COVID-19 infection as they may have obtained substantial information about COVID-19 from their doctor. In the first stage, we conducted a survey of 4000 residents of Japan. The results were independently analyzed and published [6]. These data are used as a reference in the present report.
In the second stage, we conducted a survey of 2,000 individuals in the UK and 2,000 individuals in Spain.

As this was an exploratory study, no specific hypothesis was tested. Therefore, we could not calculate the minimum required sample size. However, an estimate of 500 samples from each region is considered adequate for interregional comparison studies, and multivariate analysis requires generally ten-fold of the number of variables [9]. After consideration of the size of the research budget, we chose to obtain 2000 samples from the UK and 2000 from Spain. We chose the UK because it provides a good contrast to Japan; the UK is an island, like Japan, but has experienced a high COVID-19 infection rate. Spain was chosen as an appropriate contrast to the UK, as it has a similar high infection rate but different political and geographical characteristics. The sample sizes were calculated according to the number of questionnaire items and the feasibility of rapid data gathering. In this report, we present the data from the UK and Spain combined with those from Japan.

We used questions from a previous study [2] but added some new questions about anxiety about symptom aggravation and virus transmission. In addition to items on demographic information, the questionnaire included several items assessing levels of fear and anxiety about COVID-19-related issues, the frequency of respondents' media exposure and trust in each media source, and frequency of anti-infection behaviors. Participants provided answers on a scale from 1 (none/never) to 9 (extremely/ strongest) for items about symptoms understanding, preventive methods, health management and consulting health services if infected, levels of fear and anxiety, and the frequency of anti-infection behaviors. Items measuring the frequency of media exposure and degree of trust in each media source were rated on a scale from 1 (almost none/not at all) to 5 (very/greatly). We also asked the UK and Spain participants about the frequency of hand washing in their daily life. The questionnaire is shown in Additional file 1. We did not ask Japanese participants how many times a day they washed their hands (questionnaire item $\mathrm{F}(\mathrm{a})$ ), because this had been measured by a previous Japanese survey (shown in Additional file 1) [10].

We analyzed the data using SPSS for Windows, ver. 24 (IBM, Armonk, NY, USA). We used the $\chi^{2}$-test to analyze nominal data, analysis of variance (ANOVA) with the Games-Howell test for parametric data, and the Kruskal-Wallis test with Dunn-Bonferroni correction for non-parametric data. The level of significance was set at $p<0.05$.

The study protocol was approved by the ethics committee of Chiba University Graduate School of Medicine and the ethics committee of the International University of 
Health and Welfare before implementation. Participants were informed that their participation was voluntary. We did not gather any personally identifiable information about the responders. The participants were rewarded according to the regulations of Cross Marketing Group Inc.

\section{Results}

Between March 27 and 28, 2020, a total of 4000 participants in Japan stratified by age $(20 \mathrm{~s}, 30 \mathrm{~s}, 40 \mathrm{~s}, 50 \mathrm{~s}$, and $\geq 60$ years) and gender (400 in each group) took part in this study. Between April 17 and 21, 2020, a total of 2000 participants in the UK and 2000 participants in Spain stratified by age $(20 \mathrm{~s}, 30 \mathrm{~s}, 40 \mathrm{~s}, 50 \mathrm{~s}$, and $\geq 60$ years) and gender (200 in each group) took part in this study. Current demographic and COVID-19 data for each country are shown in Tables 1 and 2 .

We first excluded from the analysis all invalid answers, as non-serious responses may have been provided by individuals who participated in the survey just for reward. Participants who scored 1 on all items in sections $C, D, E$, and $F$ (except those assessing frequency of hand washing) were excluded. As a result, 19 participants in Japan, 13 in the UK, and 5 in Spain were excluded from this analysis. Data for the remaining 7963 participants were analyzed.

Participant' demographic data are shown in Table 1. Regarding educational background, a lower percentage of participants in Japan had university degrees than those in the UK and Spain $\left(\chi^{2}\right.$-test, Pearson $x^{2}=674.390, \mathrm{df}=6, p<0.001$, adjusted residual for university degree or above for participants in Japan $=2.4$ ). Compared with participants in the UK and Spain, a lower percentage of those in Japan had infected family or relatives $\left(\chi^{2}\right.$-test, Pearson $\chi^{2}=2055.999, \mathrm{df}=4$, $p<0.001$, adjusted residual for participants in Japan who answered "yes" $=-38.3)$ or work colleagues $\left(x^{2}-\right.$ test, Pearson $\chi^{2}=1139.305, \mathrm{df}=4, p<0.001$, adjusted residual for participants in Japan who answered "yes" $=-18.6$ ).

Table 1 The participants' demographic characteristics

\begin{tabular}{|c|c|c|c|c|c|c|}
\hline & \multicolumn{2}{|c|}{ Japan } & \multicolumn{2}{|l|}{ UK } & \multicolumn{2}{|l|}{ Spain } \\
\hline & $n$ & $\%$ & $n$ & $\%$ & $n$ & $\%$ \\
\hline \multicolumn{7}{|l|}{ Age } \\
\hline $20 \mathrm{~s}$ & 791 & 19.9 & 393 & 19.8 & 396 & 19.8 \\
\hline $30 \mathrm{~s}$ & 793 & 19.9 & 398 & 20.0 & 400 & 20.1 \\
\hline $40 \mathrm{~s}$ & 800 & 20.1 & 399 & 20.1 & 399 & 20.0 \\
\hline $50 \mathrm{~s}$ & 799 & 20.1 & 399 & 20.1 & 400 & 20.1 \\
\hline$\geq 60 \mathrm{~s}$ & 798 & 20.0 & 398 & 20.0 & 400 & 20.1 \\
\hline Total & 3981 & 100 & 1987 & 100 & 1995 & 100 \\
\hline \multicolumn{7}{|l|}{ Gender } \\
\hline Male & 1984 & 49.8 & 993 & 50.0 & 997 & 50.0 \\
\hline Female & 1997 & 50.2 & 994 & 50.0 & 998 & 50.0 \\
\hline Total & 3981 & 100 & 1987 & 100 & 1995 & 100 \\
\hline \multicolumn{7}{|l|}{ Educational background } \\
\hline Junior high school/Secondary school & 106 & 2.7 & 258 & 13.0 & 379 & 19.0 \\
\hline High school/A-level or equivalent & 1223 & 30.7 & 601 & 30.2 & 242 & 12.1 \\
\hline Diploma course or vocational school & 876 & 22.0 & 306 & 15.4 & 526 & 26.4 \\
\hline University degree or above & 1776 & 44.6 & 822 & 41.4 & 848 & 42.5 \\
\hline Total & 3981 & 100 & 1987 & 100 & 1995 & 100 \\
\hline \multicolumn{7}{|l|}{ Infected family or relatives } \\
\hline Yes & 17 & 0.4 & 498 & 25.1 & 779 & 39.0 \\
\hline No & 5909 & 95.1 & 1183 & 59.5 & 939 & 47.1 \\
\hline Uncertain & 177 & 4.4 & 306 & 15.4 & 277 & 13.9 \\
\hline Total & 3981 & 100 & 1987 & 100 & 1995 & 100 \\
\hline \multicolumn{7}{|l|}{ Infected persons in your workplace } \\
\hline Yes & 45 & 1.1 & 342 & 17.2 & 377 & 18.9 \\
\hline No & 3744 & 94.0 & 1263 & 63.6 & 1278 & 64.1 \\
\hline Uncertain & 192 & 4.8 & 382 & 19.2 & 340 & 17.0 \\
\hline Total & 3981 & 100 & 1987 & 100 & 1995 & 100 \\
\hline
\end{tabular}


Table 2 Situations in each nation at the time of survey

\begin{tabular}{|c|c|c|c|c|c|}
\hline & & & Japan & UK & Spain \\
\hline Population (per million, 2019) & & & 127 & 66.7 & 47.0 \\
\hline Date of the survey (2020) & & & 27-28 March & 17-21 April & 17-21 April \\
\hline No. of participants & & & 4000 & 2000 & 2000 \\
\hline Valid answers & & & 3981 & 1987 & 1995 \\
\hline \multicolumn{6}{|l|}{ Data at the first day of the survey: } \\
\hline Daily COVID-19 tests per thousand people & & & 0.01 (on 28 March) & 0.18 & 0.23 (on 20 April) \\
\hline \multirow[t]{2}{*}{ Cumulative infected people with COVID-19 } & & & 1,499 & 108,692 & 190,839 \\
\hline & Per capita $(/ 1,000,000)$ & & 11.8 & 1630 & 4060 \\
\hline \multirow[t]{2}{*}{ Total no. of fatal cases with COVID-19 } & & & 49 & 16,879 & 19,478 \\
\hline & Per capita $(/ 1,000,000)$ & & 0.386 & 253 & 414 \\
\hline \multirow[t]{3}{*}{ Social situation } & & Lockdown & No & Govt. order & Govt. order \\
\hline & & Restricted businesses & No & Govt. order & Govt. order \\
\hline & & Restricted going out & Voluntary & Govt. order & Govt. order \\
\hline
\end{tabular}

The data were extracted from the following: Google.com http://www.google.com Worldmeters.info https://www.worldometers.info/coronavirus/country/uk/ Our World in Data https://ourworldindata.org/coronavirus-testing

Regarding the level of knowledge about COVID-19, there were definite and significant differences between the three countries, as shown in Fig. 1. Participants in the UK and Spain had a deeper understanding of COVID-19 than those in Japan (ANOVA with Games-Howell test), at least as reflected in their subjective responses.

There were also significant between-country differences in anxiety about COVID-19 (Fig. 1). Participants in Spain were more anxious about being infected with COVID-19 than those in Japan, but less anxious than those in the UK. Participants in Japan were less afraid of infecting others with COVID-19 than those in the UK and Spain. Regarding anxiety about the severity of the disease once infected, participants in Japan were less concerned than those in the UK and Spain. Concerning the spread of COVID-19, participants in Spain were the most anxious, followed by those in the UK and then Japan.

We examined the frequency of access to and the credibility of a variety of information sources about the virus and pandemic. The survey responses revealed some country-specific characteristics (Fig. 2). Participants in Japan reported significantly less frequent access to any form of information compared with those in the UK and Spain. Remarkably, the proportion of participants in Japan who said that they had never accessed official announcements, radio, or specialists was twice as high as that of the other two countries. Participants in Spain had more frequent access than those in the UK to information sources, such as the government, a social network, radio, friends and neighbors, and specialists.

Regarding the credibility of COVID-19 information sources, participants in Japan were unlikely to trust most types of information source than those in the UK and
Spain. Participants in Spain expressed less trust in government information than participants in Japan and the UK. Social networks and friends and neighbors were not deemed credible information sources in any of the three countries, but participants in Spain reported slightly more trust in these sources than those in Japan and the UK.

We compared the frequency of daily hand washing between countries. The hand washing frequency range was 4-5 times per day in all three countries. A KruskalWallis test with Dunn-Bonferroni correction revealed that participants in Spain washed their hands significantly fewer times over the course of a day than participants in the UK $(p<0.001)$. However, the frequency of hand washing for participants in Spain was greater than that reported for participants in Japan in a previous survey $(p<0.001)[10]$.

Responses to items on precautionary behaviors are shown in Fig. 3. Among the active behaviors, patterns of hand washing and disinfectant use showed significant international differences, but these differences were complex. For example, some UK respondents washed their hands very frequently, although there were more respondents in the UK who never washed their hands compared with Spain and Japan. We also observed that $57.7 \%$ of UK participants never wore a medical mask compared with $16.1 \%$ and $9.5 \%$ of those in Spain and Japan, respectively.

We conducted an additional analysis to clarify the factors why participants in the UK avoided wearing a medical mask. A stepwise linear regression analysis was conducted in which frequency of mask wearing was the dependent variable and credibility of each information 


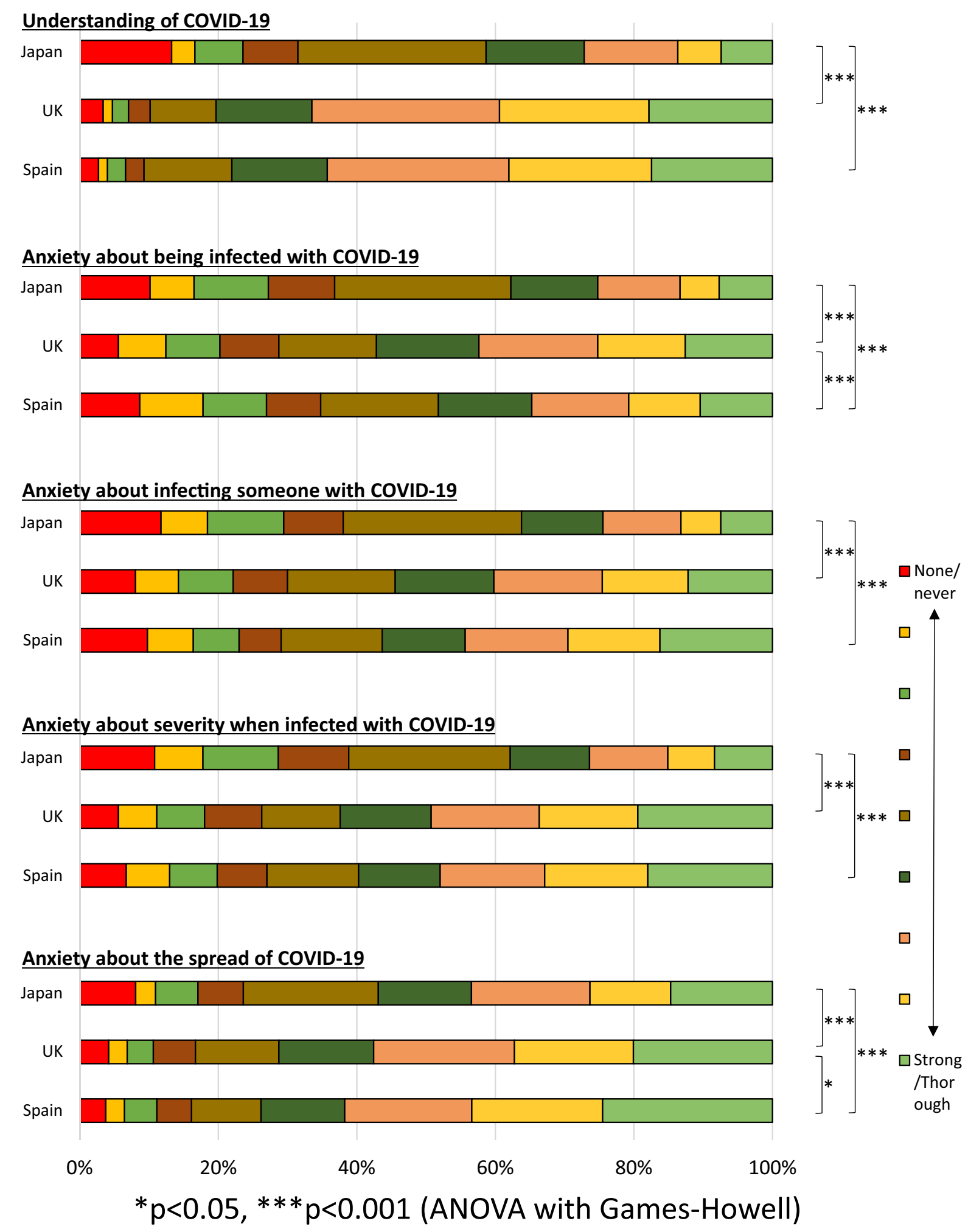

Fig. 1 Knowledge and anxiety about COVID-19 in each country 


\section{Access frequency}

Official announcement of the government
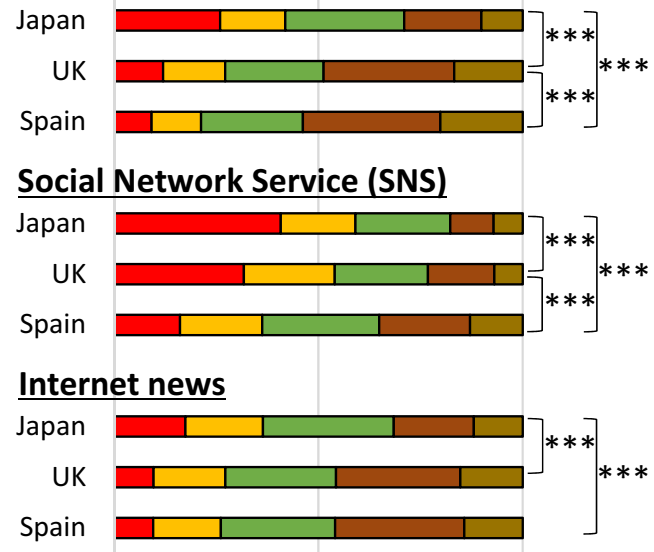

Radio (broadcast by the government excluded) Japan

UK

Spain

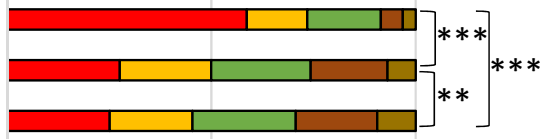

TV (broadcast by the government excluded)
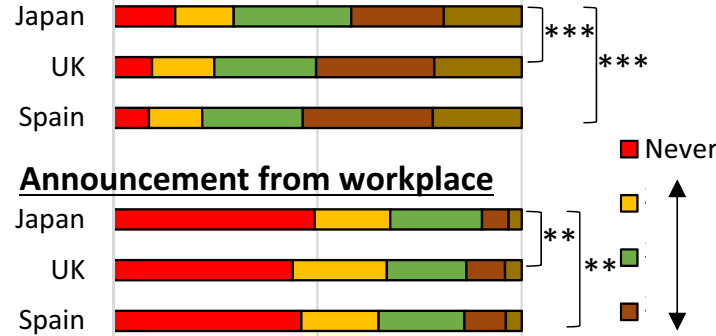

\section{Friends and neighbors}

$\square$ Frequently

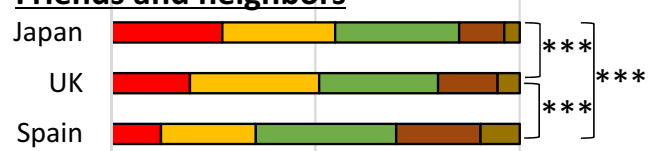

\section{Specialists}

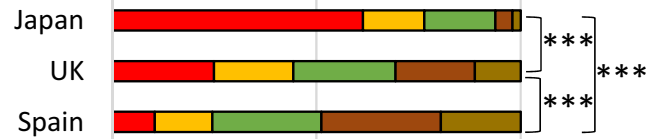

$0 \%$

\section{Credibility}

Official announcement of the government

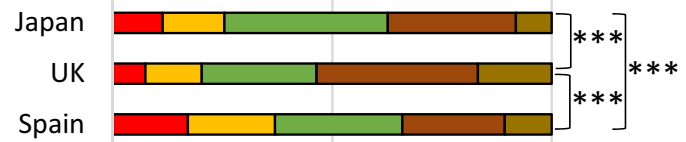

Social Network Service (SNS)

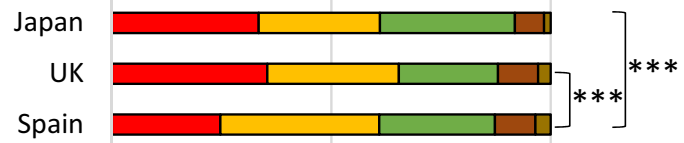

\section{Internet news}

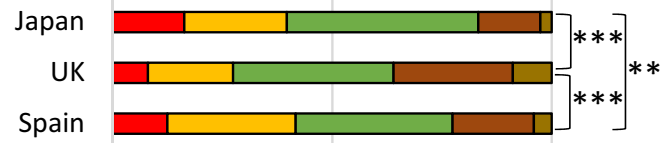

Radio (broadcast by the government excluded)

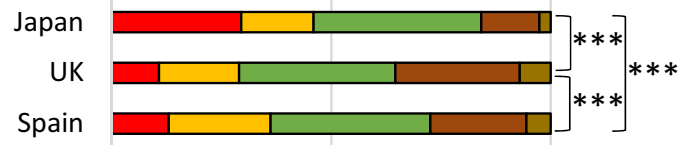

TV (broadcast by the government excluded)

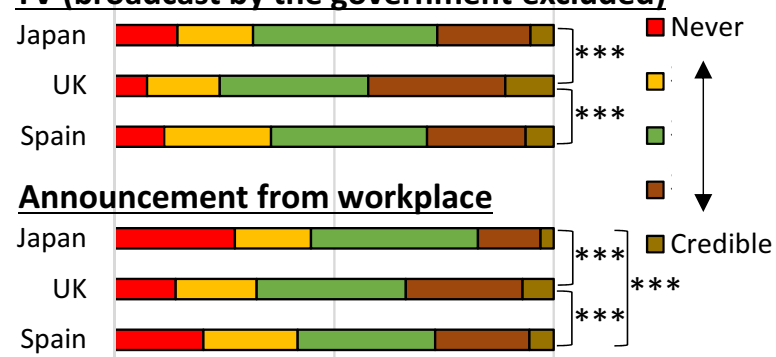

Friends and neighbors

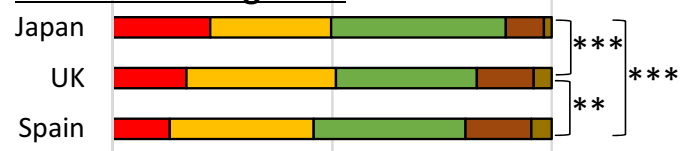

Specialists

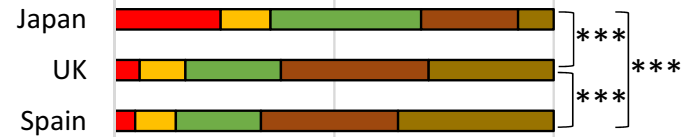

$\begin{array}{lll}0 \% & 50 \% & 100 \%\end{array}$

$* * p<0.005, * * * p<0.001$ (ANOVA with Games-Howell)

Fig. 2 Attitude toward information sources in each country

source was the independent variable. The results showed that credibility of social network services $(t=11.840$, $p<0.001)$ and friends and neighbors $(t=6.445, p<0.001)$ were positively associated with mask wearing, whereas credibility of specialists $(t=-3.902, p<0.001)$ and official announcement of the government $(t=-2.591$, $p=0.010)$ were negatively associated. In Spain, credibility of social network service $(t=4.462, p<0.01)$, friends and neighbors $(t=3.253, p=0.001)$, specialists $(t=2.667$, 
Active behaviors

Hand washing

$* p<0.05, * * * p<0.001$ (ANOVA with Games-Howell)

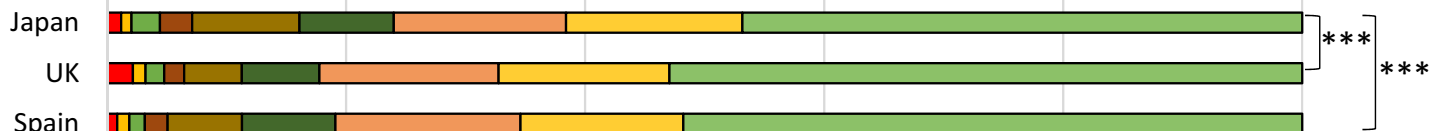

Using disinfectant

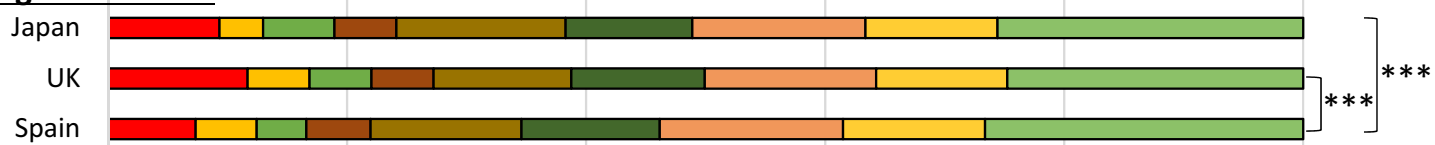

Wearing a medical mask

UK

Spain

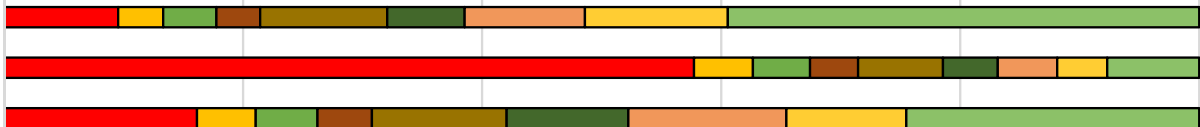

Avoidant behaviors

Avoiding people who cough or sneeze

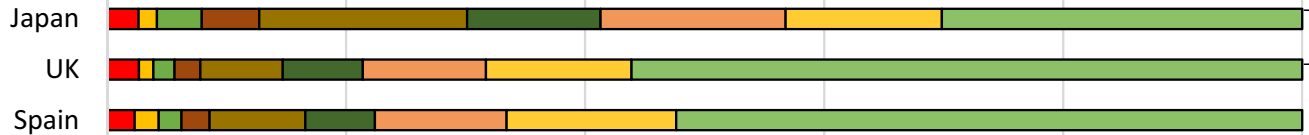

Avoiding crowded spaces

Japan

UK पमाप्य

Spain पIII |

Avoiding people who had contact with infected people

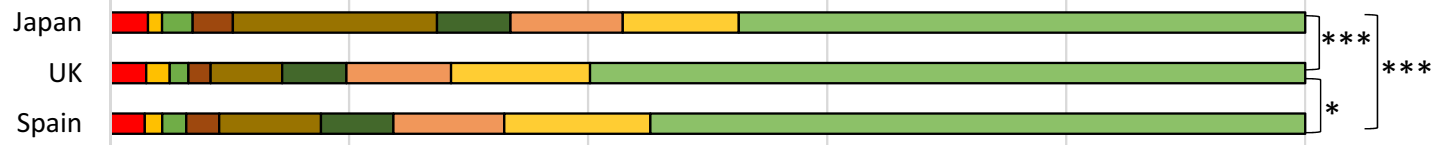

Avoiding public transport

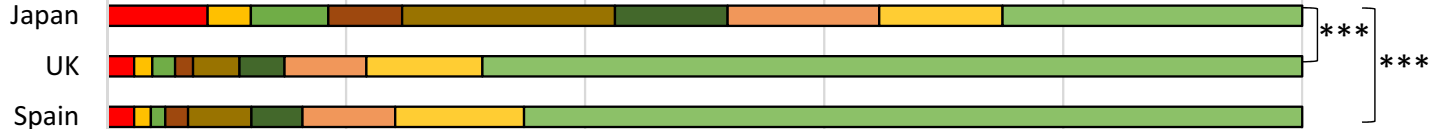

Avoiding school and work

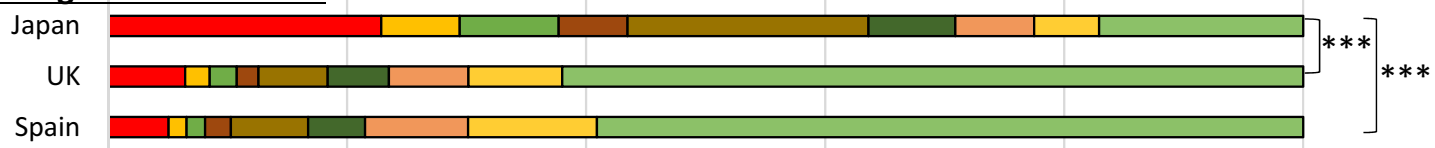

Avoiding traveling areas with high infection

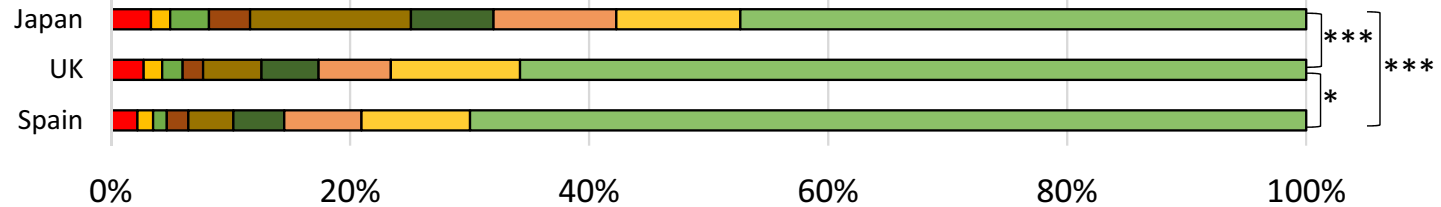

Fig. 3 Frequency of precautionary behaviors in each country 
$p=0.008)$, and TV $(t=2.253, p=0.024)$ were positively associated with mask wearing frequency.

Participants in Japan were less likely to engage in avoidance behaviors than those in the UK and Spain. Notably, participants in Japan were far less likely to avoid school or work and less likely to avoid using public transport than respondents in other countries. Most participants in the UK and Spain reported that they rarely or never went to school or work, or used public transport.

As an additional analysis, we compared data on the level of knowledge, anxiety, frequency and credibility of virus information, and precautionary behaviors between participants who had acquaintances affected by the virus and those who did not. Almost every item on the questionnaire showed a significant difference between these two groups.

We reanalyzed international differences in the items presented above by examining only participants who did not have an infected acquaintance. However, this made little difference to the results.

\section{Discussion}

We conducted an international online series of questionnaires involving a total of 8,000 individuals to investigate their knowledge, anxiety, protective behaviors, and access to information regarding COVID-19 during early spring 2020.

The data indicated that participants in the UK and Spain had a deeper understanding of COVID-19 than those in Japan. Participants in the UK and Spain also showed greater anxiety about each item than those in Japan. The frequency of access to sources of COVID-19 information was also significantly higher in the UK and Spain than in Japan.

The differences in the attitude of residents of the three countries toward COVID-19 can be explained mainly by differences in the current pandemic situation in each country. At the time of this investigation, the spread of COVID-19 in Japan was limited to several areas, but a few days after the questionnaire was administered, the number of infected people rose sharply, and the government declared a state of emergency (although in some prefectures, it was announced on April 7 [11] that residents were highly recommended to stay their homes unless it was urgent). After the end of May, the government began to gradually relax the restrictions [12]. In contrast, during the period of questionnaire administration in the UK, the spread of COVID-19 in the UK was much more severe than that in Japan. Residents were required to stay home unless there was an essential need to go out. Public business activities were prohibited, with few exceptions, until the government relaxed the restrictions on May 11, 2020 [13]. The number of deaths from COVID-19 increased linearly during the questionnaire period. In Spain, a very strict lockdown had been in place since March 14, 2020. Citizens were forbidden from leaving their homes unless necessary to obtain food or medical care, or to walk dogs. The Spanish government relaxed this regulation after a drop in the number of new infection [14], but people were required to wear face masks on public transport [15]. However, the government subsequently declared another state of emergency. To summarize, it is possible that a higher infection rate increases both anxiety and an awareness of the need for knowledge about the virus, driving the need for more precise information.

Similar international surveys have been conducted recently by other organizations. Dryhurst et al. [16] conducted an international comparison study of the perception of COVID-19 risk; they found that respondents in the UK had a higher level of risk perception than those in Japan and Spain. These results are consistent with the present findings. Gallup International also conducted a series of international surveys. The results showed that people in Japan were less likely to be anxious about catching COVID-19 than those in the UK, whereas more Japanese people reported being very or somewhat scared about COVID-19 during the period in which our questionnaire was administered [17]. Our results are generally consistent with those of other concurrent surveys.

Regarding respondents precautionary behaviors, we observed differences in the response patterns for active behaviors. Respondents in the UK and Spain more frequently washed their hands than those in Japan before the pandemic (as reported previously). To the best of our knowledge, no other reports have conducted an international comparison of three countries on hand washing frequency. It remains to be cleared why UK respondents wash their hands significantly more frequently than those in Spain.

We found notable differences in mask wearing between the countries. UK participants were far less likely to wear a mask. This difference cannot be explained by the extent of infection spread; rather, it may reflect each country's government policy and culture [18]. The WHO did not recommend that healthy people wear a face mask unless there are clear reasons to do so [18]. The UK government did not encourage citizens to wear face masks, as there is little evidence of the effectiveness of masks for preventing infection $[18,19]$. In contrast, it is well known that Japanese people are willing to wear masks partly because many individuals experience spring allergies. Approximately $40 \%$ of Japanese university students wear masks in the spring, according to a previous survey [20]. The high percentage of mask wearing in Japan before the rapid increase in symptomatic COVID-19 cases may have contributed to the reduction in the number of infectious 
cases, because wearing a mask can prevent splash infection by blocking saliva containing the virus (although it does not block the coronavirus itself) [21]. However, a recent report indicates that many SARS-CoV-2 transmissions occur from presymptomatic carriers [22]. Another recent study described the efficacy of medical mask wearing by asymptomatic individuals as well as lockdown at the population level [23].

We observed that participants in Japan were significantly less likely to engage in any of the avoidance behaviors examined than those in Spain and the UK. These results are similar to those of other concurrent surveys [17]. Leaving one's home and working outside were seriously restricted in the UK and Spain at the time of our survey, whereas in Japan, only residents in specific regions were advised (not mandated) to stay home. Workplaces were not closed in many parts of Japan at the time of this study. These situational discrepancies contributed to the differences in social activities between the countries.

A survey of Italian subjects indicated that a higher level of knowledge was positively associated with the acceptance of strict mitigation measures, such as lockdown [24]. If this finding is applicable to people in other countries, we should expect people in the UK and Spain to be more supportive of national lockdown policies than those in Japan, because the present findings indicate that the former populations have higher risk perception and anxiety. In addition, UK respondents reported a high level of trust in official information, which is consistent with a Gallup International report that UK respondents were likely to believe that their government was handling the coronavirus situation well [17]. However, our results indicate that the study population in Spain tended not to trust official information.

Our Spanish respondents were least likely to trust the government, followed by those in Japan; instead, they tended to trust specialists as a source of information. Japanese respondents trusted very few sources of information about the pandemic. Cultural factors and recent political conflicts may have contributed to these differences in basic trust in officials. It was reported very recently that many individuals in England believe conspiracy theories about COVID-19, and that these theories are associated with less adherence to official guidelines for precautionary behaviors [25]. We observed that respondents who had an acquaintance who was infected with the virus were likely to trust official information about COVID-19. These results suggest that Japanese residents may be vulnerable to conspiracy theories partly because of the (relatively rare) experience of having an infected acquaintance, although there is no evidence for the spread of COVID-19 conspiracy theories in Japan.
There are several potential study limitations. The study was conducted from March to April, 2020. The survey period differed between Japan and the other countries, which may have influenced the results. The standard of COVID-19 testing also varied between countries. In addition, as a series of web-based questionnaires was used, we cannot rule out the possibility of selection bias among participants. We obtained responses only from individuals willing to complete online questionnaires. According to the Organisation for Economic Co-operation and Development, Internet services were available for 95.8 and $91.4 \%$ of citizens in the UK and Spain, respectively, in 2019 [26]. In Japan, $79.8 \%$ of citizens used Internet services in 2019, according to the Ministry of Internal Affairs and Communications [27]. However, our participants may not be representative of the Internet users in each country because only people who had registered with the monitor database of the Cross Marketing Group Inc. Additionally, participants' residential areas may have affected the perception of COVID-19. As we did not record the residential area of participants in the UK and Spain, we could not examine the effect of area on anxiety and behavior.

\section{Conclusions}

Despite these limitations, we believe that our findings could inform policy making to control the current pandemic situation. The COVID-19 pandemic has caused widespread public anxiety. However, moderate levels of fear of infection can encourage the public to engage in protective behaviors. Therefore, it is important that the government and other authorities provide precise unbiased information (that is not overly optimistic) about the seriousness of the current situation.

Our findings indicate several international differences in public perception and behaviors during the COVID-19 pandemic. These differences suggest the need to establish region- and country-specific solutions. For example, in Spain, providing accurate information through nonofficial channels, such as social network services, would be beneficial, because many people do not trust official announcements. In contrast, compensation for absence from work may encourage people in Japan to avoid work and public transport. In the UK, the low rate of mask wearing and relatively high trust in the government suggest that an official framework to encourage individuals to wear medical masks would help mitigate the spread of COVID-19.

\section{Supplementary Information}

The online version contains supplementary material available at https://doi. org/10.1186/s12991-021-00334-6. 
Additional file 1. This file is the whole content of the questionnaire.

\section{Abbreviations}

ANOVA: Analysis of variance; COVID-19: Coronavirus disease 2019; SARS-CoV-2: Severe acute respiratory syndrome coronavirus 2; UK: United Kingdom; WHO: World Health Organization.

\section{Authors' contributions}

MI initially proposed this study. All the authors discussed the study protocol. AS developed the web questionnaire form. OK contributed to the translation of the questionnaire into English. AS gathered the data via Cross Marketing Group Inc. AS, TN, OK, and KI statistically analyzed the data. All the authors discussed the interpretation of the results. AS mainly wrote the manuscript. MI administered the entire research project. All the authors read and approved the final manuscript.

\section{Funding}

This study was conducted with a management grant provided by Japan's Ministry of Education, Culture, Sport, Science and Technology [MECSST] to Chiba University Graduate School of Medicine and by a grant from the Japan Society for the Promotion of Science [JSPS] KAKENHI [to T.N., no. JP19K08066]. The MECSST and JSPS had no role in or control over the execution of this study.

\section{Availability of data and materials}

All data generated or analyzed during this study are included in this published article.

\section{Ethics approval and consent to participate}

The study protocol was approved by the ethics committee of Chiba University Graduate School of Medicine and the ethics committee of the International University of Health and Welfare before implementation. Participants were informed that their participation was voluntary. Participants were rewarded according to the regulations of Cross Marketing Group Inc.

\section{Consent for publication}

We did not gather any personally identifiable information about participants.

\section{Competing interests}

The authors declare that they have no competing interests regarding this study.

\section{Author details}

${ }^{1}$ Center for Forensic Mental Health, Chiba University, 260-8670 Inohana 1-8-1, Chuo-ku, Chiba, Japan. ${ }^{2}$ Department of Psychiatry, Graduate School of Medicine, Chiba University, Chiba, Japan. ${ }^{3}$ Department of Psychology, International University of Health and Welfare, Akasaka, Japan. ${ }^{4}$ Department of Psychiatry, School of Medicine, International University of Health and Welfare, Narita, Japan. ${ }^{5}$ Department of Cognitive Behavioral Physiology, Graduate School of Medicine, Chiba University, Chiba, Japan.

Received: 13 September 2020 Accepted: 1 February 2021

Published online: 18 February 2021

\section{References}

1. Shigemura J, Ursano RJ, Morganstein JC, Kurosawa M, Benedek DM. Public responses to the novel 2019 coronavirus (2019-nCoV) in Japan: Mental health consequences and target populations. Psychiatry Clin Neurosci. 2020;74(4):281-2. https://doi.org/10.1111/pcn.12988.

2. Jones JH, Salathé M. Early assessment of anxiety and behavioral response to novel swine-origin influenza A(H1N1). PLOS ONE. 2009:4(12):e8032. https://doi.org/10.1371/journal.pone.0008032.

3. Harper CA, Satchell LP, Fido D, Latzman RD. Functional fear predicts public health compliance in the COVID-19 pandemic. Int J Mental Health Addict. 2000. https://doi.org/10.1007/s1 1469-020-00281-5.

4. Kamel Boulos MN, Geraghty EM. Geographical tracking and mapping of coronavirus disease COVID-19/severe acute respiratory syndrome coronavirus 2 (SARS-CoV-2) epidemic and associated events around the world: how 21 st century GIS technologies are supporting the global fight against outbreaks and epidemics. Int J Health Geogr. 2020;19(1):8.

5. Li YK, Peng S, Li LQ, Wang Q, Ping W, Zhang N, Fu XN. Clinical and transmission characteristics of covid-19-a retrospective study of 25 cases from a single thoracic surgery department. Curr Med Sci. 2020;40(2):1-6.

6. Shiina A, Niitsu T, Kobori O, et al. Relationship between perception and anxiety about COVID-19 infection and risk behaviors for spreading infection: a national survey in Japan. Brain Behav Immun Health. 2020. https://doi.org/10.1016/j.bbih.2020.100101.

7. World Health Organization. Coronavirus disease 2019 (COVID-19). Situation Report-66 Data as reported by national authorities by 10:00 CET 26 March 2020. https://www.who.int/docs/default-source/coronaviru se/situation-reports/20200326-sitrep-66-covid-19.pdf?sfvrsn=9e5b8 b48_2.

8. Bults M, Beaujean DJMA, Richardus JH, Voeten ACVM. Perceptions and behavioral responses of the general public during the 2009 influenza A (H1 N1) pandemic: a systematic review. Disaster Med Public Health Prep. 2015;9(2):207-19. https://doi.org/10.1017/dmp.2014.160.

9. Sakai T. How to conduct a questionnaire survey. Nikkei Bunko. 2001. Nihon Keizai Shimbunsha; Tokyo. [in Japanese]

10. Dimsdrive. A questionnaire survey regarding hand washing, sense of hygiene, and using hand soap. (in Japanese) 2015. http://www.dims. ne.jp/timelyresearch/2015/151115/

11. Kyodo News. Japan PM Abe declares state of emergency amid widespread virus infections. 2020. https://english.kyodonews.net/ news/2020/04/ac4415709921-abe-to-declare-state-of-emergencyamid-widespread-virus-infections.htm

12. Japan Times. Japan to lift coronavirus state of emergency in 39 prefectures. 2020. https://www.japantimes.co.jp/news/2020/05/14/national/ japan-coronavirus-emergency-39-prefectures/\#.Xr34FWj7Sck

13. BBC, Lockdown update: What are the new rules set out by Boris Johnson? 2020. https://www.bbc.com/news/explainers-52530518

14. World Economic Forum. Three of the world's hardest-hit nations are preparing to end their lockdowns. 2020. https://www.weforum.org/ agenda/2020/04/three-of-the-worlds-hardest-hit-nations-are-prepa ring-to-end-their-lockdowns/

15. Independent. Coronavirus: Spain makes face masks compulsory on public transport as country begins to ease strict lockdown. 2020. https ://www.independent.co.uk/news/world/europe/coronavirus-facemasks-spain-public-transport-lockdown-pedro-sanchez-a9496031. html

16. Dryhurst S, Schneider CR, Kerr J, et al. Risk perceptions of COVID-19 around the world. J Risk Res. 2020. https://doi.org/10.1080/13669 877.2020 .1758193$.

17. YouGov. COVID-19 Public Monitor. 2020. https://yougov.co.uk/topics/ international/articles-reports/2020/03/17/fear-catching-covid-19

18. World Health Organization. Advice on the use of masks the community, during home care and in health care settings in the context of the novel coronavirus (2019-nCoV) outbreak. Interim guidance. 2020. https ://www.who.int/docs/default-source/documents/advice-on-the-useof-masks-2019-ncov.pdf?sfvrsn=40619336 1 \&download=true

19. Express and Star. What is the UK advice on wearing face masks? 2020. https://www.expressandstar.com/news/uk-news/2020/04/28/what-isthe-uk-advice-on-wearing-face-masks/

20. Morishima M, Kishida K, Uozumi T, Kamijo M. An investigation of the use of hay fever masks for the youth. J Hum Ergol (Tokyo). 2011;40(1-2):151-6.

21. ScienceMag.org. Not wearing masks to protect against coronavirus is a 'big mistake,' top Chinese scientist says. 2020. https://www.sciencemag .org/news/2020/03/not-wearing-masks-protect-against-coronaviru s-big-mistake-top-chinese-scientist-says

22. He X, Lau EHY, Wu P, et al. Temporal dynamics in viral shedding and transmissibility of COVID-19. Nat Med. 2020;26(5):672-5. https://doi. org/10.1038/s41591-020-0869-5.

23. Stutt ROJH, Retkute R, Bradley M, Gilligan CA, Colvin J. A modelling framework to assess the likely effectiveness of facemasks in combination with "lock-down" in managing the COVID-19 pandemic.' Proc R Soc A. 2020;476:20200376. https://doi.org/10.1098/rspa.2020.0376g. 
24. Zanin GM, Gentile E, Parisi A, Spasiano D. A Preliminary Evaluation of the Public Risk Perception Related to the COVID-19 Health Emergency in Italy. Int J Environ Res Public Health. 2020. https://doi.org/10.3390/ ijerph17093024.

25. Freeman D, Waite F, Rosebrock L, et al. Coronavirus conspiracy beliefs, mistrust, and compliance with Government Guidelines in England.

Psychol Med. 2020;21:1-30. https://doi.org/10.1017/S00332917200018 90.

26. OECD data. https://data.oecd.org/ict/internet-access.htm
27. Ministry of Internal Affairs and Communications. (in Japanese) https:// www.soumu.go.jp/johotsusintokei/whitepaper/ja/r01/html/nd232120. html

\section{Publisher's Note}

Springer Nature remains neutral with regard to jurisdictional claims in published maps and institutional affiliations.
Ready to submit your research? Choose BMC and benefit from:

- fast, convenient online submission

- thorough peer review by experienced researchers in your field

- rapid publication on acceptance

- support for research data, including large and complex data types

- gold Open Access which fosters wider collaboration and increased citations

- maximum visibility for your research: over $100 \mathrm{M}$ website views per year

At BMC, research is always in progress.

Learn more biomedcentral.com/submissions 